\title{
Problem of Breast Cancer Management in the Obstetric- Gynecologic Department of the National Hospital Donka, Teaching Hospital-Conakry
}

\author{
Camara $\mathrm{MK}^{1^{*}}, \mathrm{Sy}^{2}{ }^{2}$, Léno DWA ${ }^{1}$, Diawara $\mathrm{F}^{1}$, Traoré $\mathrm{B}^{3}$, Hijazi $\mathrm{Y}^{1}$ and Kéita $\mathrm{N}^{1}$ \\ ${ }^{1}$ Department of Obstetric Gynecology, National Hospital Donka, Guinea \\ ${ }^{2}$ Department of Obstetric Gynecology, Ignace Deen National Hospital, Guinea \\ ${ }^{3}$ Oncology Surgery Unit, National Hospital Donka, Guinea
}

"Corresponding Author: Dr. Camara MK, Department of Obstetric Gynecology, National Hospital Donka, Guinea, E-mail: camarakanta@gmail.com

Received: 07 January 2018; Accepted: 01 February 2018; Published: 08 February 2018

\begin{abstract}
Objective: Describe the diagnosis, therapeutic and prognostic aspects of breast cancer and analyze the survival rate of patients.

Materials and methods: We conducted a quasi-retrospective descriptive and analytic study of 4 years from $1^{\text {st }}$ January 2010 to $31^{\text {st }}$ December 2013, folders of women histologically confirmed with breast cancer and consent was gotten through telephone contact. We described clinical and therapeutic characteristics, survival analyses was done using Epi-info 3.5, SPSS version 18 software with a significance level $\mathrm{p}<0.05$ and survival by Kaplan Meier.

Results: Breast cancer was confirmed in $12.62 \%$ with 3 -month waiting time for histology result in clinically advanced stages (89.5\%) and infiltrating ductal carcinoma (64.61\%).

Patients were aged $47.5 \pm 8.5$ years old, multiparous (66.69\%), housewife (69.23\%), uneducated $(67.70 \%)$, referred $(98.46 \%)$ and treated with chemotherapy for an overall survival of $23.07 \%$ at 5 years.

Conclusion: Infiltrating ductal carcinoma of the breast is frequent in the clinically advanced stage, treated with chemotherapy for uncertain survival at 5 years. Improving the survival and quality of life of women requires sensitization and training of women and health providers in breast palpation for early detection and treatment.
\end{abstract}

Keywords: Breast; Cancer; Diagnosis; Treatment; Survival 


\section{Introduction}

Breast cancer is the leading cancer among women in developed and developing countries in terms of incidence and mortality. It is a major public health problem [1]. Worldwide, 540,000 cases of breast cancer occur every year and nearly 300,000 women die from it, usually because of late screening [2]. Some reduction in risk can be achieved through prevention, the strategies of which cannot eliminate the majority of breast cancers that appear in low- and middle-income countries where the disease is diagnosed at very advanced stages [2]. A significant number of cancers can be treated by surgery, radiotherapy, chemotherapy and hormone therapy, especially if detected early enough. The lack of diagnostic means and the unavailability of certain therapeutic methods make the management of breast cancer very difficult for practitioners. Our study aims to describe the diagnosis, therapeutic and prognostic aspects and to evaluate the factors influencing the prognosis and survival rate of patients suffering from breast cancer.

\section{Materials and Methods}

It was a quasi-retrospective descriptive and analytic study carried out over a period of 4 years from January 1st, 2010 to December 31st, 2013. We collected the folders of women consulted for breast cancer at the Francophone Research and Training Center for Prevention of Gynecological Cancers (CERFFO-PCG), confirmed histologically at the Laboratory of Anatomy pathology and treated at the obstetric gynecologic department of the National Hospital Donka of the teaching hospital of Conakry. The vital records at the date of point on 12/31/2013 of some nonresponding patients collected was reported on an anonymous survey after obtaining their consent and the assurance for ethical confidentiality by telephone network. We describe the clinical and therapeutic characteristics using Microsoft office World 2007 and the survival analysis (age, level of enrollment and clinical stage), was done using the software, Epi-info 3.5 and SPSS version 18 with a threshold of significance $p<0.05$, and survival by the method of Kaplan Meier.

\section{Results}

We found 65 cases of histologically confirmed for breast cancer in 515 gynecologic cancers diagnosed and confirmed at the Department of Donka National Pathology, 12.62\% (Figure 1).

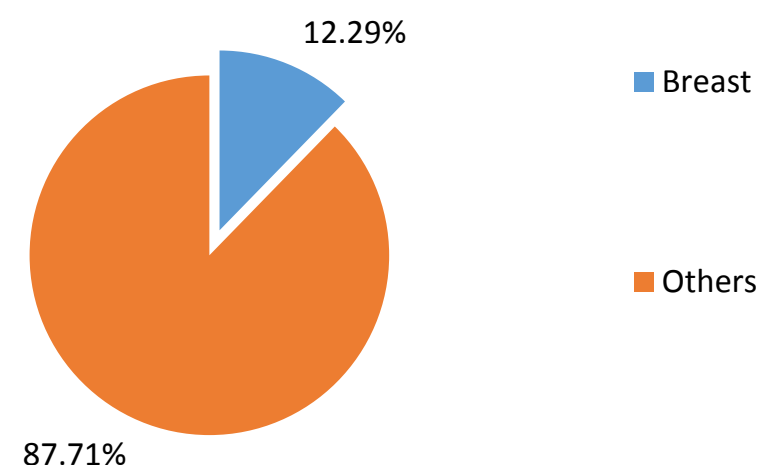

Figure 1: Patient distribution by frequency of cancer sites. 
Text 1: Socio-demographic characteristics (continuation).

\begin{tabular}{|c|c|c|c|}
\hline \multicolumn{2}{|l|}{ Sociodemographic characteristic } & Total & $\%$ \\
\hline \multicolumn{2}{|l|}{ Age (Year) } & & \\
\hline & $25-34$ & 11 & 16.92 \\
\hline & $35-44$ & 23 & 35.38 \\
\hline & $45-54$ & 10 & 18.46 \\
\hline & $55-64$ & 12 & 15.88 \\
\hline & $65-74$ & 4 & 12.31 \\
\hline & 75 years and + & 5 & 7.7 \\
\hline \multicolumn{4}{|l|}{ Parity } \\
\hline & Nullipares & 8 & 12.31 \\
\hline & Primipares & 2 & 3.08 \\
\hline & Paucipares & 11 & 16.92 \\
\hline & Multipares & 24 & 36.92 \\
\hline & Large multipares & 20 & 30.77 \\
\hline \multicolumn{4}{|l|}{ Niveau d'instruction } \\
\hline & Uneducated & 44 & 67.69 \\
\hline & Educated & 21 & 32.31 \\
\hline \multicolumn{4}{|l|}{ Profession } \\
\hline & Housewife & 45 & 69.23 \\
\hline & Emplyee & 13 & 20 \\
\hline & Traders & 7 & 10.77 \\
\hline
\end{tabular}

Table 1: Distribution by socio-demographic characteristics.

- Conakry: $45 / 65$ (69.23\%)

$>$ Outside Conakry: 20/65 (30.77\%).

- Patient Orientation:

$>$ Referred: $37 / 65$ (56.92\%)

$>$ Coming by himself: $28 / 65$ (43.08\%)

- Delayed in diagnosis: 12.62 months.

- Confirmation period: 3 months.

Text 2: The presence of metastasis at diagnosis time was 7.69\% with 5 sites including 3 pulmonary and 2 hepatic and 4 cases of bilateral breast cancer. Brachial pain and lymphoedema post mastectomy were the complications recorded. 


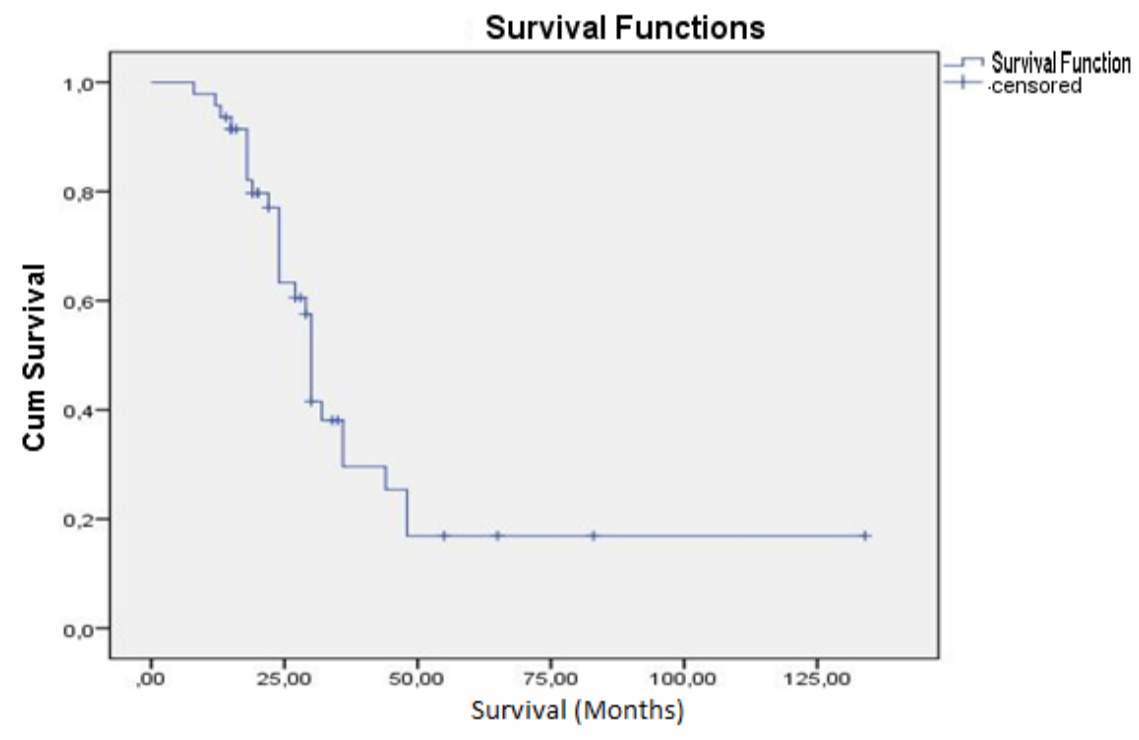

Figure 2: The study population.

The study population was characterized by young people of an average age of 47.5 years with extremes of 25 and 84 years, multiparous (Table 1), and housewives (69.23\%), uneducated with $67.7 \%$ (Table 2).

\begin{tabular}{|l|l|l|}
\hline Clinical stage & Number & \% \\
\hline $\mathrm{T}_{3} \mathrm{~N}_{1} \mathrm{M}_{0}$ & 9 & 13.84 \\
\hline $\mathrm{T}_{3} \mathrm{~N}_{2} \mathrm{M}_{\mathrm{x}}$ & 14 & 16.92 \\
\hline $\mathrm{T}_{4} \mathrm{~N}_{1} \mathrm{M}_{\mathrm{x}}$ & 14 & 21.54 \\
\hline $\mathrm{T}_{4} \mathrm{~N}_{2} \mathrm{M}_{\mathrm{x}}$ & 19 & 21.54 \\
\hline $\mathrm{T}_{4} \mathrm{~N}_{2} \mathrm{M}_{1}$ & 9 & 13.84 \\
\hline Total & $\mathbf{6 5}$ & $\mathbf{1 0 0}$ \\
\hline
\end{tabular}

Table 2: Distribution of patients by clinical stage.

The patients were from Conakry, the capital, 45 (69, 23\%) and out of Conakry: 20 (30.77\%), with a health care provider $37(56.92 \%)$ and $(43.08 \%)$ came without been escorting by health personnel, The diagnosis was delayed about 12.62 months and the confirmation was delayed about 3 month, diagnosis (Text 1) for clinically advanced lesions classified as T4 49 (75.4\%) and T3 9 (13.84\%) (Table 3). 


\begin{tabular}{|l|l|l|}
\hline Anatomy- pathologic result & Number & \% \\
\hline Infiltrating ductal carcinoma & 42 & 62.68 \\
\hline Mixed carcinoma & 4 & 06.15 \\
\hline Undifferentiated breast carcinoma & 2 & 03.07 \\
\hline Carcinomatous mastitis & 2 & 03.07 \\
\hline Mucosal secreting duct & 1 & 1.54 \\
\hline Carcinoma NOS * & 14 & 21.56 \\
\hline
\end{tabular}

Table 3: Distribution of patients according to the anatomical-pathological examination result (WHO).

The most frequent tumors were ductal carcinoma infiltrating 42 (64.61\%) and Carcinoma NOS 14 (21.56\%) (Table 4).

\begin{tabular}{|l|l|l|}
\hline Methods of treatment & Number & \% \\
\hline Neoadjuvant chemotherapy & 25 & 65.78 \\
\hline Surgery + Chemotherapy + Radiotherapy & 5 & 13.16 \\
\hline Surgery + Chemotherapy & 4 & 10.53 \\
\hline Palliative & 4 & 10.53 \\
\hline Total & $\mathbf{3 8}$ & $\mathbf{1 0 0 . 0 0}$ \\
\hline
\end{tabular}

Table 4: Distribution of patients by type of treatment.

With 5 metastatic sites (including 3 pulmonary and 2 liver) and 4 cases of bilateral breast cancer (Text 2), unspecified histo-prognostic grade on the report. Regarding to the treatment, 38 (58.5\%) patients were treated with neoadjuvant chemotherapy (65.81\%), surgery associated with chemotherapy and radiotherapy $5(13.15 \%)$ or chemotherapy 4 (10.52\%), and palliation with analgesics 4 (10.52\%) (Table 5).

\begin{tabular}{|l|l|l|}
\hline Vital Status & Number & \% \\
\hline Dead & 36 & 55.38 \\
\hline Alived & 15 & 23.07 \\
\hline Lost to follow up & 14 & 21.55 \\
\hline Total & $\mathbf{6 5}$ & $\mathbf{1 0 0}$ \\
\hline
\end{tabular}

Table 5: Distribution according to the vital status on the date of point on 31/12/2013.

The chemotherapy protocol used was FAC 14 (41.18\%) followed by FEC75 / 100, 10 (29.41\%), CMF and AT5 $(14.70 \%)$ each (Table 6). 


\begin{tabular}{|c|c|c|c|c|c|}
\hline \multirow{2}{*}{\multicolumn{2}{|c|}{$\begin{array}{l}\text { Anatomo- pathology } \\
\text { Age }\end{array}$}} & \multicolumn{2}{|c|}{ Dead (36) } & \multicolumn{2}{|c|}{ Alived (29) } \\
\hline & & $\mathrm{n}$ & $\%$ & $\mathrm{n}$ & $\%$ \\
\hline & $<45$ yrs & 24 & 36.92 & 10 & 15.38 \\
\hline & $\geq 45 \mathrm{yrs}$ & 12 & 18.46 & 19 & 29.23 \\
\hline \multicolumn{6}{|l|}{ Educational level } \\
\hline & No education & 26 & 40 & 18 & 27.69 \\
\hline & Primary & 2 & 3.07 & 2 & 3.07 \\
\hline & Secondary & 8 & 12.3 & 5 & 7.69 \\
\hline & Tertiary & 0 & 0 & 4 & 6.15 \\
\hline \multicolumn{6}{|l|}{ Clinical stage } \\
\hline & T3N1M0 & 2 & 3.08 & 7 & 10.77 \\
\hline & T3N2M0 & 6 & 9.2 & 8 & 12.31 \\
\hline & T4N1M0 & 6 & 9.23 & 8 & 12.31 \\
\hline & T4N2M0 & 13 & 20 & 6 & 9.23 \\
\hline & T4N2M1 & 9 & 13.85 & 0 & 0 \\
\hline
\end{tabular}

Table 6: Distribution of patients according to selected risk factors.

At the 31 st/12/1214 as a date of point, 15 patients were alived at $23.1 \%, 14$ (21.55\%) were lost to follow up and 36 (55.38\%) died. Among the survival factors studied, we found a relationship between the occurrence of breast cancer before and after 45 years with a statistically significant for $\mathrm{p}=0.000364$. However, no relation was found with education and clinical status. Overall survival was $50 \%$ at 30 months and $23.1 \%$ at 5 years (Figure 2).

\section{Discussion}

Breast cancer is the 2nd most common cancers recorded in our department (Figure 1), in a proportion superimposed on the cancer profile of $11.5 \%$ in Guinea according to IARC in 2014 [2]. However, it is and remains the number one female cancer in the world, with $23 \%$ in Morocco [3] and $44.3 \%$ in Benin [4]. The mean age is below 50 years (Table 1), reported in 2008 by Maalej M. et al. In Tunisia [5], corroborates to the multiparity $(67.69 \%)$ related to fertility (Table 1). However, pregnancy protects the breast by modifying the breast cells in the direction of greater differentiation. The earlier this first pregnancy occurs, the better it acts [6]. Maternity protection only occurs when breast cancer occurs at menopause [7]. The predominance of school drop out of women (Table 1) is certainly related to the low enrollment rate of girls of $48 \%$ in primary and $11 \%$ in secondary schools in Guinea in 2005 [8] and early sexual intercourse. The school drop out for early or forced marriages could explain the high rate of married women in our series.

The high rate of residents (texe1) could be explained by the activities of the French Regional Center for Training and Prevention of Gynecological Cancers (CERFFO-PCG) in Conakry since 2007. It would be related to the improvement of urbanization, adoption Of Western lifestyles and in the long run the life expectancy of 59 years of Guinean women in 2014) [2]. The major delay in diagnosis, is less than 8.47 months in Morocco [3], is related to lack of knowledge of the breast cancer signs, late consultation and retention of patients in seeking for health facilities for care (Text 1). The financial, transport and correspondence problems in Conakry and the lack of skills in 
the provinces contribute to the second delay in the treatment of non-residents. The third delay in the provision of care is due to the long waiting time in histological confirmation related to laboratory dysfunction. The diagnosis of breast cancer is made with metastasis at a rate (Text 2), lower than the $15.78 \%$ as described by Didi K et al. In Côte d'Ivoire in 2011. [12] The high incidence of infiltrating ductal carcinoma (Table 3), is confirmed in the literature in Morocco in 2015 by Sofia A. et al [3] and Benin by Tonato JA [4].

Diagnosis at a locally advanced stage of $T_{3} \mathrm{~N}_{1} \mathrm{M}_{\mathrm{x}}$ to $\mathrm{T}_{4} \mathrm{~N}_{2} \mathrm{M}_{\mathrm{x}}$ at a rate (Table 2) higher than that of $78 \%$ in Cameroon [9] due to lack of financial resources, motivating the choice of neo adjuvant chemotherapy at a rate (Table 5) higher than ours, by $69 \%$ in the series of Essiben $\mathrm{F}$ et al. In Cameroon [9]. Of the recommended chemotherapy combinations, Fuoro-uracil + Adriamycin + Cyclophosphamide (F.A.C), was the most prescribed (Table 4). Among the beneficiaries, only nine patients $(9.23 \%)$ had received a complete cure of 6 sessions in the service due to a lack of financial means. The high cost of chemotherapy, at 2,280,000 Guinean francs (GNF), is 162,857 CFA francs or 325.71 US dollars per session, ie 13,680,000 GNF or 977,143 CFA francs, compared with 50,000 CFA francs per session, ie., 300,000 CFA francs per session Institute of Dakar.

The low rate of chemotherapy following surgery (Table 4) compared to $23.1 \%$ in Cameroon [9], or associated with radiotherapy in Dakar, was certainly related to late diagnosis at a locally advanced stage of disease. Patients are referred to Senegal or Morocco for radiotherapy. With a cost of 150,000 CFA francs (2,100,000 GNF) in Dakar, excluding other costs related to airfare, 3,500,000 GNF (261,194.03F CFA), pre-therapeutic examinations, To livelihood and travel. The low socioeconomic status did not allow some patients to cope with non-subsidy treatments created by the state. We agree with some authors that management may also be affected at several levels: difficulty adhering to the plan of care, poor adherence, or discontinuation of treatment and lost to follow up [5, 10]. The high rate of patients lost to follow-up (Table 5) is related to self-satisfaction with the reduction in tumor mass or lack of catch-up by phone contact due break down of the Sotelgui Telephony Company.

Complications (Text 2) were higher than the 5.26\% reported in the Oncology Surgery Unit (UCO) [11], including brachial pain and post-mastectomy lymphedema (Text 2). The rate of metastases at diagnosis (Text 2) with pulmonary and hepatic localizations was twice as high of 15.78\% in 2011 in Côte d'Ivoire [12]. As of 31/12/2013, patients who died in the department (Table 5) were more than half metastasized. Breast cancer survival rates varied widely from country to country, ranging from $80 \%$ or more in North America, Sweden and Japan to close to $60 \%$ in middle-income countries, and Less than $40 \%$ in low-income countries. Survival in 2013 (Figure 2) is much lower with $57 \%$ at 2 years and 50\% at 5 years in Egypt in 1996 [13].

Low survival rates in less developed countries can be explained mainly by the lack of early screening programs, which result in a high proportion of women with advanced disease, Infrastructure for diagnosis and appropriate treatment [14]. Educational attainment and clinical stage were factors that did not influence patient survival. Age $<45$ years is related to survival with a statistically significant difference with $\mathrm{p}=0.00036$ (Table 6). 


\section{Conclusion}

Infiltrating ductal carcinoma-type breast cancer is common with late diagnosis at the clinically advanced stage, treated with chemotherapy with uncertain survival at 5 years. Sensitization and training of women and providers in breast palpation for early screening and treatment with radical surgery could improve the survival and quality of life of women.

\section{References}

1. Ferlay J, Shin HR, Bray F, et al. GLOBOCAN 2008 v 2.0. Cancer Incidence and Mortality Worldwide: IARC Cancer Base No. 10. 2010. Lyon, France. International Agency for Research on Cancer.

2. OMS. Profil des pays pour Cancer. Lyon, France. Centre International du Registre des Cancer (2014).

3. Aloulou S, Mahfoudi AE, Omrani AE, et al. Facteurs liés au diagnostic tardif du cancer du sein: expérience du CHU Mohammed VI Marrakech. The Pan African Medical Journal 21 (2015): 162.

4. Tonato Bangnan JA, Denakpo JL, Aguida B, et al. Epidémiologie des cancers gynécologiques et mammaires à l'Hôpital de la Mère et de 1 'Enfant-Lagune (HOMEL) et à la clinique universitaire de gynécologie obstétrique (CUGO) de Cotonou, Bénin. Bull cancer 100 (2013): 141-146.

5. Maalej M, Hentati D, Messai T, et al. Breast cancer in Tunisia in 2004: a comparative clinical and epidemiological study. Bull Cancer 95 (2008): E5-E9.

6. Faupel-Badger JM, Arcaro KF, Balkam JJ, et al. Postpartum remodeling, lactation, and breast cancer risk: summary of a National Cancer Institute-sponsored workshop. J Natl Cancer Inst 105 (2013): 166-174.

7. Poggi MM. Carcinoma of the Female Breast. In: DeCherney AH, Nathan L, Goodwin MT, et al. Current Diagnosis and Treatment Obstetrics and Gynecology, Tenth Edition. New-York. The McGraw-Hill Companies (2006).

8. Direction Nationale de la Statistique (DNS) (Guinée) et ORC Macro. Enquête Démographique et de Santé (EDS), Guinée 2005. Calverton, Maryland, USA : DNC et ORC (2006): 21-26.

9. Essiben $\mathrm{F}$, Foumane $\mathrm{P}, \mathrm{Mboudou} \mathrm{E}$, et al. Diagnostic et traitement du cancer du sein au Cameroun à propos de 65 cas. Mali méd 10 (2013): 3-13.

10. Parkin DM, Ferlay J, Hamdi-Cherif M, et al. Whelan Sleds. Cancer in Africa: epidemiology and prevention Lyon: IARC Press, IARC Scientific Publication (2003): 414.

11. Traoré B, Doualan ED, Diallo Y, et al. La problématique de la prise en charge du cancer du sein de diagnostic post opératoire à propos de 19 cas à l'UCO de Donka. Journal Africain du cancer, Août 2 (2010): 140-145.

12. Didi K, Coulibaly J, Diabaté A, et al. Collaboration oncologue, radiologue et pathologiste dans la détermination pré-thérapeutique des récepteurs hormonaux et de Her2 dans les cancers du sein inopérables d'emblée en Côte d'Ivoire, résultats préliminaires. Carcinol Clin Afrique 20 (2011).

13. Awad AT, el Husseini G, Anwar M, et al. Bilateral primary breast cancer: a clinicopathological study of the second primary. Int Surg 81 (1996): 57-60. 
14. Coleman MP, Quaresma M, Berrino F, et al. Cancer survival in five continents: a worldwide populationbased study (CONCORD). Lancet Oncol 9 ((2008): 730-756.

15. Bloom HJG, Richardson WW. Histological Grading and Prognosis in Breast Cancer. A study of 1409 cases of which 359 have been followed for 15 years. Br J Cancer 11 (1957): 359-377.

Citation: Camara MK, Sy T, Léno DWA, Diawara F, Traoré B, Hijazi Y and Kéita N. Problem of Breast Cancer Management in the Obstetric-Gynecologic Department of the National Hospital Donka, Teaching Hospital-Conakry. Journal of Cancer Science and Clinical Therapeutics 2 (2018): 9-17.

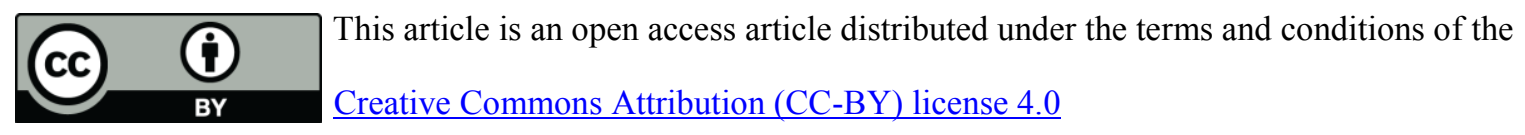

